\title{
Radiographies under Traction Influence Surgeon Choice in Implant Selection for Intertrochanteric Fractures
} \author{
Fontenelle $^{5}$, Hélio J. A. Fernandes ${ }^{6}$, Fernando B. Reis ${ }^{6}$ and Marco A. P. Andrade ${ }^{1}$ \\ ${ }^{1}$ Department of Orthopaedics and Traumatology at Federal University of Minas Gerais. Belo Horizonte (MG), Brazil. \\ ${ }^{2}$ Department of Orthopaedics and Traumatology, Hospital de Misericórdia, Santos Dumont (MG), Brazil. \\ ${ }^{3}$ Department of Orthopaedics and Traumatology, Felício Rocho Hospital, Belo Horizonte (MG), Brazil. \\ ${ }^{4}$ Department of Orthopaedics and Traumatology, Santa Casa Hospital, Belo Horizonte (MG), Brazil. \\ ${ }^{5}$ Department of Orthopaedics and Traumatology, Federal University of Rio de Janeiro, Rio de Janeiro (RJ), Brazil. \\ ${ }^{6}$ Department of Orthopaedics and Traumatology, Federal University of São Paulo (SP), Brazil.
}

Robinson E.S Pires ${ }^{\star 1,3}$, Bruno G. S. Souza ${ }^{2}$, Marcos. L. Leite ${ }^{3}$, Ricardo H. Miranda ${ }^{4}$, Marcos T. C. Lopes ${ }^{4}$, Carlos F. T. Barros ${ }^{4}$, César R. C.

\begin{abstract}
Objective: Determine whether preoperative AP pelvis radiographies under manual traction influence surgeon choice for implants in intertrochanteric fractures compared with standard radiographies.

Methods: Fifty-eight patients with intertrochanteric fractures were prospectively enrolled from four tertiary teaching hospitals. All patients had standard AP pelvis radiographies taken as well as radiographies under manual traction of affected limb, 116 images total. Three fellowship trained trauma surgeons and three hip surgeons blindly reviewed the images and indicated their implant choice for each case: extra or intramedullary fixation. The observers received randomly assigned images and were unaware of the radiography technique, patient number, and repetition of patients within the set of images. Statistical analyses were performed using Cohen Kappa method and McNemar, $\mathrm{Q}$ Cochran, and Wilcoxon tests.

Results: Manual traction radiographies changed surgeon-implant choice in $35.06 \%$ (range: $27.6 \%$ to $43.1 \%$ ) However, traction radiographies provided no improvement in weak inter-observer reliability for treatment indication ( $k=0.264, p<0.001)$ compared to standard radiographies $(k=0.220, p<0.001)$, when using Mann-Whitney test $(p=0.359)$. Traction views did not increase predilection for either method. Hip surgeons agreed more than trauma surgeons concerning implant choice.
\end{abstract}

Conclusions: Manual traction radiographies modified surgeon choice in up to one third of intertrochanteric fracture cases.

Keywords: Intertrochanteric fractures; Trochanteric fractures; Femur fractures; Hip Fractures; Radiographies; Reliability

\section{Introduction}

Intertrochanteric femoral fractures are life-threatening lesions common in the elderly. The lesions may decrease life expectancy and quality [1]. Appropriate treatment normally includes surgery; however implant design and surgical techniques lack a uniform standard and may vary according to fracture type, bone quality, patient characteristics, implant availability, and surgeon choice.

Recent data have suggested that some unstable fracture patterns, such as reverse obliquity, and highly comminuted, could benefit from intramedullary nailing. Other fracture patterns could be treated preferably with extramedullary implants such as sliding screw plates. Although disagreement exists concerning treatment, it is well established that adequate radiographs and fracture classifications can provide useful guidelines for surgeon choice.

Emergency department radiographies are reportedly of bad quality, due to several factors, especially poor patient positioning. Nonetheless reports exist of centers focusing on improving radiography quality to facilitate surgeon choice for techniques and implants. Traction views can improve residents and inexperienced surgeons to correctly classify proximal femur fractures [2].

The literature contains no studies evaluating the impact of traction views on surgeon implant choice. This study however was designed to demonstrate the real importance of traction X-ray to select better fixation method for intertrochanteric fractures.

\section{Materials and Methods}

Fifty-eight patients with intertrochanteric femoral fractures were prospectively enrolled from four tertiary teaching hospitals. All patients received standard AP pelvis radiographies as well as radiographies under manual traction of affected limb, total 116 images total. Films were photographed using a 3.2 megapixel digital camera and converted into jpeg extension files. Files were named randomly and recorded to digital media.

Standard technique for regular AP pelvis radiographies consisted of supine whole pelvis radiographs with X-ray beam centered on pubic symphysis, directed vertically, 1 meter from film. Patients were allowed to lie at rest with hips naturally extended.

A similar technique was applied for traction views, but also involved manual traction exerted by a trained orthopedic surgeon on

*Corresponding author: Robinson Esteves Santos Pires, Department of Orthopaedics and Traumatology, Felício Rocho Hospital, Avenida do Contorno 9530, Barro Preto, Belo Horizonte (MG), CEP:30110-934, Brazil, Tel. +55-31-3514-7007; E-mail: robinsonesteves@ig.com.br

Received March 05, 2012; Accepted April 20, 2012; Published April 23, 2012

Citation: Pires RES, Souza BGS, Leite ML, Miranda RH, Lopes MTC, et al. (2012) Radiographies under Traction Influence Surgeon Choice in Implant Selection for Intertrochanteric Fractures. J Trauma Treat 1:131. doi:10.4172/2167-1222.1000131

Copyright: (c) 2012 Pires RES, et al. This is an open-access article distributed under the terms of the Creative Commons Attribution License, which permits unrestricted use, distribution, and reproduction in any medium, provided the original author and source are credited. 
the affected limb until reaching the length of the other leg, combined with hip internal rotation. Patients received no anesthesia but were administered IV opioids fifteen minutes prior to exam.

Three fellowship trained trauma surgeons and three hip surgeons blindly reviewed the images and recommended the best implant for each case: intramedullary fixation, involving cephalomedullary nail or extramedullary fixation, involving standard Dynamic hip screw (DHS) plating. Surgeons were familiar with both techniques. These observers received randomly assigned images and were unaware of the radiography technique, patient number, and repetition of patients within the set of images. If they determined the image was insufficient to indicate the appropriate implant, observers could refrain from choosing a technique. Decisions were recorded on a standard spreadsheet, and data were tabulated using Microsoft Excel Software, subsequently analyzed by a blinded reviewer. Observers were uninvolved in the data collection, digital file recording, and statistical analyses.

Inter-observer reliability for dichotomous data was obtained using Cohen Kappa statistics, and normality of the data using Wilcoxon test. McNemar test determined whether treatment choice changes occurred randomly, or if a trend existed towards one implant type with use of traction views. Q Cochran test was used as an extension for McNemar test in sets of more than 2 observers. Results were considered significant at $\mathrm{p}<0.05[3,4,5]$.

The research received Institutional review board (IRB) approval from all participating institutions and was done in accordance with the Helsinki declaration of 1975.

\section{Results}

Proximal femur manual traction views induced change in surgeonselected implant in $35.06 \%$ of cases (range: $27.6 \%$ to $43.1 \%$ ), shown in Table 1. Traction views prompted no increased predilection for either method. When divided by surgical specialty, two trauma surgeons chose more intramedullary fixation devices, while the other chose more extramedullary fixation devices, when traction views were analyzed. Among hip surgeons, one chose more intramedullary implants, while another extramedullary implants, and the other had no change in preference, when traction views were considered, shown in Table 1.

The opinion change percentage was not statistically different among observers, demonstrated by the $\mathrm{p}$ value of the proportion test for specialist pair (range from 0.076 to $>0.99$ ), shown in Table 2 .

A weak inter-observer reliability for treatment indication $(\mathrm{k}=0.264$, $\mathrm{p}<0.001)$ was obtained when regular views were considered. The traction views provided weak reliability $(\mathrm{k}=0.220, \mathrm{p}<0.001)$. According to Mann-Whitney test $(\mathrm{U}=1.534 ; \mathrm{p}=0.359)$, traction views provided no improvement in inter-observer reliability for implant choice.
Reliability among observer pairs was analyzed using Kappa method for radiographies without and with traction, Tables 3 and 4 respectively. For views without traction, agreement between trauma surgeons for implant selection was weak to absent ( $\mathrm{k}$ range $=0.052$ to 0.296 ; $\mathrm{p}$-value range $=0.024$ to 0.739$)$. For traction views, the agreement was weak to absent ( $\mathrm{k}$ range $=0.012$ to $0.234 ; \mathrm{p}$-value range $=0.072$ to 0.927 ). Among hip surgeons, agreement on views without traction improved but still ranged from weak to fair $(\mathrm{k}$ range $=0.342$ to $0.534 ; \mathrm{p}$-value range $=<0.001$ to 0.001 ). Similarly, their agreement on views with traction was weak to fair $(\mathrm{k}$ range $=0.241$ to 0.505 ; $\mathrm{p}$-value range $=<0.001$ to 0.05 ).

\section{Discussion}

Traction views of the fractured proximal femur are often reported as important elements in diagnosis and surgical planning [1,6]. However, limited scientific data exists to support widespread use. Potential benefits of traction views include improved ability to classify the fracture [2]. Although the views may influence treatment choice, the present study was the first to prove their practical implication. In fact, surgeon decision may change in up to one third of cases. Similar results were reported in viewing other joints [7]. In wrist fractures, Goldwyn et al. [7] reported that traction views were invaluable in adequate interpretation of fracture patterns and surgical technique.

Drawbacks exist concerning regular use of traction views. They include additional trained personnel in the radiology room, radiation exposure of the person applying traction, patient pain and discomfort from positioning, need for more analgesia, and additional cost. Some authors suggest such risks could be outweighed by increased correct diagnoses [2] (Figure 1).

The present study demonstrated a weak agreement among surgeons despite the radiograph obtained. This agreement caused little surprise as it represents a major controversy encountered in the literature. There is little consensus on the best implant for each fracture. Additionally, a grey zone seems to exist where both implants could be indicated [8-10]. To avoid such controversy, the authors could have focused on whether traction views would change surgeon ability to correctly identify fracture patterns; however other authors have addressed this issue [6]. More importantly, the focus of the present study was more practical and referred to the ability of one diagnostic method to influence surgical decision making. Although obvious confounding factors exist in the process of selecting an implant or surgical technique, such as surgeon preference and training, implant availability, and patient characteristics, the present study demonstrated that adequate visualization of the fracture patterns plays a major role in decision making.

The authors noticed that traction views induced no preference for one implant type. Despite the surgical subspecialty, changes of opinions

\begin{tabular}{|c|c|c|c|c|}
\hline Observer & Percentage of opinion change with traction views (IC95) & Trend in change of choice (with traction views) & McNemar's test & $P$ value \\
\hline 1 (trauma surgeon) & $31 \%(19.5$ to $44.5 \%)$ & Towards extramedular & 5.062 & $0.008^{*}$ \\
\hline 2 (hip surgeon) & $29.3 \%(18.1$ to $42.7 \%)$ & None & 0.062 & 0.629 \\
\hline 3(trauma surgeon) & $43.1 \%(30.1$ to $56.8 \%)$ & Towards Intramedular & 4.762 & $0.004^{*}$ \\
\hline 4(trauma surgeon) & $39.6 \%$ (24 to $53.3 \%$ ) & Towards Intramedular & 1.189 & $0.035^{*}$ \\
\hline 5 (hip surgeon) & $27.6 \%(16.7$ to $40.9 \%)$ & Towards Intramedular & 7.562 & $0.004^{*}$ \\
\hline 6 (hip surgeon) & $39.7 \%$ (27 to $53.3 \%)$ & Towards extramedular & 8.522 & $0.004^{*}$ \\
\hline
\end{tabular}

Table 1: Percentage of opinion change and trend in method choice with traction view. 
Citation: Pires RES, Souza BGS, Leite ML, Miranda RH, Lopes MTC, et al. (2012) Radiographies under Traction Influence Surgeon Choice in Implant Selection for Intertrochanteric Fractures. J Trauma Treat 1:131. doi:10.4172/2167-1222.1000131

Page 3 of 3

\begin{tabular}{|l|l|l|l|l|l|}
\hline P value & Observer 2 & Observer 3 & Observer 4 & Observer 5 & Observer 6 \\
\hline Observer 1 & 0.84 & 0.175 & 0.33 & 0.685 & 0.33 \\
Observer 2 & - & 0.118 & 0.238 & 0.837 & 0.238 \\
Observer 3 & $\mathrm{X}$ & - & 0.706 & 0.076 & 0.706 \\
Observer 4 & $\mathrm{X}$ & $\mathrm{X}$ & - & 0.165 & $>0.99$ \\
Observer 5 & $\mathrm{X}$ & $\mathrm{X}$ & $\mathrm{X}$ & $\mathrm{X}$ & 0.165 \\
\hline
\end{tabular}

Note: repeated values $(X)$ were omitted for better visualization.

Table 2: Interobserver comparison of opinion change with traction view.

\begin{tabular}{|l|l|l|l|l|l|}
\hline Observer & $\begin{array}{l}\text { 2 (hip } \\
\text { surgeon) }\end{array}$ & $\begin{array}{l}\text { 3 (trauma } \\
\text { surgeon) }\end{array}$ & $\begin{array}{l}\text { 4(trauma } \\
\text { surgeon) }\end{array}$ & $\begin{array}{l}\text { 5 (hip } \\
\text { surgeon) }\end{array}$ & $\begin{array}{l}\text { 6 (hip } \\
\text { surgeon) }\end{array}$ \\
\hline 1(trauma & $\mathrm{k}=0.479^{*}$ & $\mathrm{k}=0.052$ & $\mathrm{k}=0.038$ & $\mathrm{k}=0.579$ & $\mathrm{k}=0.459^{*}$ \\
surgeon) & $\mathrm{p}<0.001$ & $\mathrm{p}=0.628$ & $\mathrm{p}=0.739$ & $\mathrm{p}<0.001$ & $\mathrm{p}<0.001$ \\
2 (hip surgeon) & - & $\mathrm{k}=0.063$ & $\mathrm{k}=0.254$ & $\mathrm{k}=0.342^{*}$ & $\mathrm{k}=0.378^{*}$ \\
& & $\mathrm{p}=0.628$ & $\mathrm{p}=0.052$ & $\mathrm{p}=0.001$ & $\mathrm{p}<0.001$ \\
3(trauma surgeon) & $\mathrm{X}$ & - & $\mathrm{k}=0.296^{*}$ & $\mathrm{k}=0.076$ & $\mathrm{k}=0.116$ \\
& & $\mathrm{p}=0.025$ & $\mathrm{p}=0.426$ & $\mathrm{p}=0.212$ \\
4(trauma surgeon) & $\mathrm{X}$ & $\mathrm{X}$ & - & $\mathrm{k}=0.114$ & $\mathrm{k}=0.092$ \\
& & & & $\mathrm{p}=0.258$ & $\mathrm{p}=0.348$ \\
5 (hip surgeon) & $\mathrm{X}$ & $\mathrm{X}$ & $\mathrm{N}$ & - & $\mathrm{k}=0.534^{*}$ \\
& & & & & $\mathrm{p}<0.001$ \\
\hline
\end{tabular}

Note: repeated values $(X)$ were omitted for better visualization. Values with $\left(^{*}\right)$ are considered statistically significant.

Table 3: Inter-observer reliability for views without traction.

\begin{tabular}{|c|c|c|c|c|c|}
\hline Observer & $\begin{array}{l}2 \text { (hip } \\
\text { surgeon) }\end{array}$ & $\begin{array}{l}3 \text { (trauma } \\
\text { surgeon) }\end{array}$ & $\begin{array}{l}\text { 4(trauma } \\
\text { surgeon) }\end{array}$ & $\begin{array}{l}5 \text { (hip } \\
\text { surgeon) }\end{array}$ & $\begin{array}{l}6 \text { (hip } \\
\text { surgeon) }\end{array}$ \\
\hline 1(trauma surgeon) & $\begin{array}{l}k=0.743^{*} \\
p<0.001\end{array}$ & $\begin{array}{l}k=0.225 \\
p=0.072\end{array}$ & $\begin{array}{l}k=0.012 \\
p=0.927\end{array}$ & $\begin{array}{l}k=0.345^{*} \\
p=0.008\end{array}$ & $\begin{array}{l}k=0.546^{*} \\
p<0.001\end{array}$ \\
\hline 2 (hip surgeon) & - & $\begin{array}{l}k=0.276^{*} \\
p=0.018\end{array}$ & $\begin{array}{l}k=0.124 \\
p=0.301\end{array}$ & $\begin{array}{l}k=0.241^{*} \\
p=0.05\end{array}$ & $\begin{array}{l}k=0.505^{*} \\
p<0.001\end{array}$ \\
\hline 3(trauma surgeon) & $x$ & - & $\begin{array}{l}k=0.234^{*} \\
p=0.074\end{array}$ & $\begin{array}{l}k=0.172 \\
p=0.185\end{array}$ & $\begin{array}{l}k=0.180 \\
p=0.161\end{array}$ \\
\hline 4(trauma surgeon) & $x$ & $x$ & - & $\begin{array}{l}k=0.034 \\
p=0.792\end{array}$ & $\begin{array}{l}k=0.039 \\
p=0.764\end{array}$ \\
\hline 5 (hip surgeon) & $x$ & $x$ & $x$ & - & $\begin{array}{l}k=0.448^{*} \\
p=0.001\end{array}$ \\
\hline
\end{tabular}

Note: repeated values $(\mathrm{X})$ were omitted for better visualization. Values with $\left(^{*}\right)$ are considered statistically significant.

Table 4: Inter-observer reliability for views without traction.

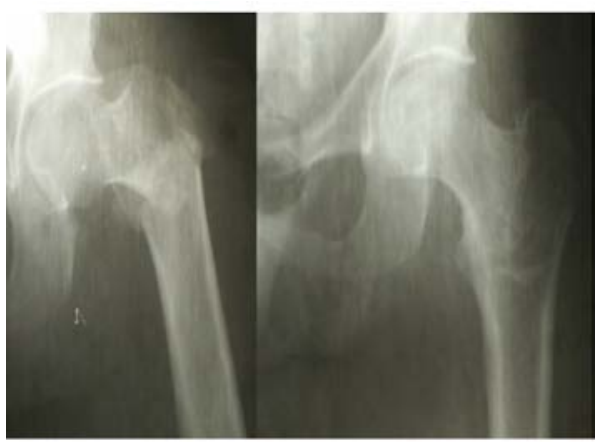

Figure 1: Radiographs of the same fractured hip with and without traction Regular AP radiographs may be misleading. towards intramedullary and extramedullary implants occurred. Agreement among trauma surgeons was lower than hip surgeons, although both were generally low. This does not mean however, that the choices were inadequate. The study contained no gold standard treatment to make such comparisons. Some current evidence points benefits of extramedullary implants for stable intertrochanteric fractures. While intramedullary nailing should be reserved for unstable patterns, consensus is far from unanimous regarding fractures involving the lateral femur cortices and heavily comminuted calcar region fractures.

The study had several limitations. As mentioned, no gold standard of implant choice existed to compare the specialist indications. Therefore, this was a level III diagnostic study. Randomization and blinding techniques were used to minimize risk bias. Additionally, selection bias may have been diminished by the study design with prospective collection of a consecutive series of patients without data loss and with a multicentric setting. The radiographs obtained were representative of the universe of fractures generally faced by surgeons, including stable and unstable fractures with multiple patterns. Although surgeons were selected from different subspecialties and hospitals, they may not represent orthopedic surgeons overall, thereby compromising the external validity of the findings. Additionally, the authors used no classification methods which may complicate reproducibility.

Nonetheless, a relevant and valid answer has been reached to a primary question. It can be concluded that in up to one third of cases, traction views of the proximal femur with intertrochanteric fractures may have direct influence on surgeon choice of implants and surgical technique.

\section{References}

1. Baumgaertner MR, Higgins TF (2006) Fratura do colo do fêmur. Em: Rockwood CA Jr, DP Green, RW Bucholz, eds. Rockwood e Green Fraturas em adultos, $5^{\mathrm{a}}$ edição, Volume 2. Philadelphia, PA: JB Lippincott; Edição Brasileira 15791588.

2. Koval KJ, Oh CK, Egol KA (2008) Does a traction-internal rotation radiograph help to better evaluate fractures of the proximal femur? Bull NYU Hosp Jt Dis 66: 102-106.

3. Pestana MH, Gageiro JN (1998) Análise de dados para ciências sociais - A complementaridade do SPSS. Lisboa Silabo.

4. http://www.worldcat.org/title/estatistica-nao-parametrica-para-ciencias-docomportamento/oclc/246909590?tab=details

5. Landis JR, Koch GG (1977) The measurement of observer agreement for categorical data. Biometrics 33: 159-174.

6. Koval KJ, Zuckerman JD (2006) Fraturas intertrocantéricas. In: Rockwood CA Jr, DP Green, RW Bucholz, edtn Rockwood e Green Fraturas em adultos, 5 edição, Volume 2. Philadelphia, PA: JB Lippincott; Edição Brasileira 16351680.

7. http://www.hwbf.org/ota/am/ota10/otapo/OTP10005.htm

8. http://www.actafisiatrica.org.br/v1/controle/secure/Arquivos/AnexosArtigos/27 23D092B63885E0D7C260CC007E8B9D/vl_08_n_03_113_119.pdf

9. Canto RST, Silveira MA, Rosa AS, Gomide LC, Baraúna MA (2003) Morfologia radiográfica de quadril e pelve e sua relação com fraturas proximais do fêmur. Revista Brasileira de Ortopedia. 38: 12-20.

10. Gnudi S, Ripamonti C, Gualtieri G, Malavolta N (1999) Geometry of proxima femur in the prediction of hip fracture in osteoporotic women. $\mathrm{Br} \mathrm{J}$ Radiol 72 729-733. 